\title{
LA NARRATIVA BOLIVIANA DEL SIGLO XXI. LECTURAS EN TORNO A LA TOMA DEL MANUSCRITO DE SEBASTIÁN ANTEZANA
}

\author{
MAGDALENA GONZÁLEZ ALMADA ${ }^{11}$ \\ Universidad Nacional de Córdoba \\ Av. Olmos $4352^{\circ}$ piso, $B^{\circ}$ Centro, Córdoba, Argentina. C.P:5000 \\ magdagonzalezalmada@hotmail.com
}

\section{RESUMEN}

En la producción literaria contemporánea de Bolivia se produce un fenómeno en el que las obras se desmarcan de la tradición literaria del siglo XX y con ello abandonan los géneros que, durante al menos la primera mitad del siglo pasado, caracterizaban la narrativa boliviana. De este modo el indigenismo y el costumbrismo son dejados de lado para pasar, en la primera década del siglo XXI, a otros géneros que se condigan más con las preocupaciones y las indagaciones que los escritores más jóvenes enfrentan en los albores del presente siglo. En la obra La Toma del Manuscrito (2008), Sebastián Antezana revisa y retoma la tradición literaria universal para superar la tradición literaria boliviana. Mientras en La fotografía y la traducción, se encarna un proceso de desdoblamiento y de ocultamiento del artista -detrás de una cámara, detrás de una lengua- aportando a la narrativa boliviana una novela escrita a partir de lugares poco visitados en esta narrativa del siglo XX.

Palabras clave: narrativa boliviana, género literario, tradición, fotografía, traducción.

\footnotetext{
${ }^{11}$ Licenciada en Letras Modernas (Facultad de Filosofía y Humanidades, Universidad Nacional de Córdoba-Argentina). Doctoranda en Letras por la misma institución. Investigadora del Centro de Investigaciones de la Facultad de Filosofía y Humanidades, Universidad Nacional de Córdoba.
} 
THE BOLIVIAN NARRATIVE OF THE XXI CENTURY. LECTURES CONCERNING LA TOMA DEL MANUSCRITO BY SEBASTIÁN ANTEZANA.

\section{ABSTRACT}

In the literary contemporary production of Bolivia, it takes place a phenomenon in which the works decouple of the literary tradition of the XX century and then, they leave the genres that, during at least the first half of the last century, were characterizing the Bolivian narrative. This way the indigenismo and the costumbrism are set aside to pass, in the first decade of the XXI century, to other genres that convey better the worries and the inquiries that the youngest writers face at the beginning of the present century. In the work La Toma del Manuscrito (2008), Sebastián Antezana checks and retakes the literary universal tradition to overcome the literary Bolivian tradition. Meanwhile, in La fotografía y la traducción, there is personified a process of unfolding and concealment of the artist - behind a camera, behind a language - contributing to the Bolivian narrative with a novel written from places hardly visited in this narrative of the XX century.

Keywords: Bolivian narrative, literary genre, tradition, photography, translation

\section{Introducción}

La narrativa y ensayística bolivianas produjeron durante el siglo XX una literatura íntimamente ligada a la preocupación sociológica, de clase o racial, a la problemática de la definición de un sujeto nacional o de proyectos de nación que pudieran en alguna medida aproximarse a una idea relativamente homogénea de "Io boliviano". Así, el hilo conductor del canon del siglo XX se nutre principalmente de obras indigenistas como Raza de Bronce (1919) de Alcides Arguedas y costumbristas como La Chaskañawi (1947) de Carlos Medinaceli, de ensayos sociológicos como Pueblo Enfermo (1909) de Arguedas, Creación de la Pedagogía Nacional (1910) de Franz Tamayo o Nacionalismo y Coloniaje (1943) de Carlos Montenegro. Lugar aparte merecen las obras que integran la llamada 
literatura minera con obras como Socavones de Angustia (1947) de Fernando Ramírez Velarde y El precio del Estaño (1960) de Néstor Taboada Terán, entre otras y el ciclo de la Guerra del Chaco que se inaugura con Sangre de Mestizos (1936) de Augusto Céspedes y culmina con Laguna H3 (1961) de Adolfo Costa du Rels. Se observa una apelación a los hechos históricos, a los sujetos sociales efectivamente existentes (indígenas), a los sujetos sociales imaginados (indígenas y cholos transformados en mestizos letrados) y a los sujetos sociales en el ejercicio del poder (mestizos y criollos). Luego del fracaso de la Revolución del 52, la narrativa se vuelca sobre sí misma, apartándose de la interpelación, negando "la protección del Estado" (Felipe Delgado (1979) de Jaime Sáenz), absteniéndose de la preocupación racial (aparecen personajes no definidos físicamente como en Los Deshabitados (1957) de Marcelo Quiroga Santa Cruz o en los cuentos de Cerco de Penumbras (1957) de Oscar Cerruto) y deja de lado el tono costumbrista de las novelas de escenario rural.

A principios del siglo $X X I$, la realidad boliviana da un vuelco tanto en lo social como en lo político. Luego de la Guerra del Agua (2002), en Cochabamba y de la Guerra del Gas (2003) en La Paz, las configuraciones sociales y también las literarias parecen haber mudado en sus intereses. Con la asunción de Evo Morales en el año 2005, se abandona el modelo neoliberal impuesto durante la década de 1980, iniciándose un nuevo período político y social. En este contexto resulta una tarea necesaria continuar con la indagación sobre lo que tiene para aportar la narrativa boliviana, teniendo en consideración que esta producción ha crecido notablemente a nivel de posibilidades de publicación, premios e incentivos para la producción literaria.

\section{Tradición y rupturas}

Tal como aparece en Marxismo y Literatura de Raymond Williams, la tradición se entiende como un concepto dinámico en el que se implica no solo la referencia al pasado, sino también la "selección" de la producción ubicada en ese pasado: "la tradición es en la práctica la expresión más evidente de las presiones y límites dominantes y hegemónicos" (Williams, 2009, p.158). Esa tradición da cuenta de las pulsiones que operaron para que cierta producción literaria fuera 
luego referenciada e incluso invocada como "legitimante" de una producción futura. En una tradición literaria se materializan los intereses del discurso hegemónico que en el caso de Bolivia referían, entre otros aspectos, a cuestionarse sobre el rol del indio y del cholo, el papel del Estado y el diseño territorial y social del país.

Así, la tradición se construyó en base a las obras ligadas al indigenismo y al costumbrismo en la primera mitad del siglo $\mathrm{XX}$ y toma como referentes a Jaime Sáenz, Jesús Urzagasti y Néstor Taboada Terán, entre otros, para la segunda mitad del siglo. Escapan a esta tradición obras que plantean otras inquietudes, novedades estilísticas, obras únicas de autores que luego se dedicaron a la actividad política, como el caso de Marcelo Quiroga Santa Cruz, entre otros casos aislados de escritores que quedaron fuera del canon 0 de cualquier otra institucionalidad referida a la producción literaria, ya que estamos en presencia de "un proceso deliberadamente selectivo y conectivo que ofrece una ratificación cultural e histórica de un orden contemporáneo" (William, 2009, p.160).

Como plantea Williams (2009), la tradición selectiva es una "conexión en que se utiliza una versión del pasado con el objeto de ratificar el presente e indicar direcciones para el futuro" (p.160). Estas concepciones referidas a la tradición resultan operativas en nuestra investigación a los fines de observar de qué modo ha sido desplazada, dejada conscientemente de lado, con mayor énfasis en algunos autores jóvenes. En ese sentido, entendemos que han existido durante los últimos años, transformaciones políticas y sociales que suponen transformaciones en el ámbito literario. Desde ese punto de vista, se ha tomado a la tradición literaria boliviana, a su estudio y cuestionamiento, como una punta de lanza que referirá acerca de lo que la narrativa contemporánea toma y abandona en razón a esa tradición.

En el estudio que llevamos a cabo basándonos en la producción narrativa de la primera década del siglo XXI, observamos que algunos autores toman distancia de esa tradición e incluso pretenden desmarcarse de la misma. Esta decisión responde a alejarse de la "repetición", es decir, algunos autores jóvenes no quieren correr el riesgo de repetir viejas fórmulas que ya se pusieron en juego 
en la narrativa boliviana del siglo pasado, por considerarlas gastadas o pasadas de moda, por un lado. Por otro, intentan superar el imaginario que descansa sobre la narrativa de Bolivia, ampliamente extendida, como una producción de tema indigenista o costumbrista que transcurre en escenarios rurales. Otro aspecto es que se procura trascender las fronteras nacionales escribiendo novelas que puedan ser leídas por cualquier lector, no solo el boliviano; se apuesta a una literatura cosmopolita (esto implica, además, un alejamiento de "lo andino") que refiera a cualquier lector y a cualquier lugar provocando que los niveles de identificación sean más amplios.

En el caso de La toma del manuscrito (2008) de Sebastián Antezana, novela que constituye en esta ocasión el centro de nuestro análisis, observamos que se apela a la "superación" de la tradición literaria de Bolivia. Esta ruptura se observa en el espacio en el que transcurren los hechos narrados, debido a que, concretamente, estos se desarrollan en África e Inglaterra; sus personajes pertenecen a la clase letrada europea. Por lo tanto, se abandona el estereotipo andino del indígena o del cholo que se encuentra en el ámbito rural. La toma del manuscrito es una obra cuya acción transcurre muy lejos del imaginario referido al altiplano.

Asimismo, y este es el dato -quizás- más relevante, no se trata de una novela ni indigenista ni costumbrista. El género como forma clasificatoria, ayuda en este caso a pensar cuánto se aleja Antezana y su novela de la tradición. Así, La toma del manuscrito plantea como novedad el enmarcarse en el relato policial, poco cultivado en la narrativa boliviana del siglo XX, utilizando la fotografía y la traducción como elementos distintivos. La novela explícitamente aclara que posee un prólogo y un epílogo escritos por S. narrador y traductor de la misma. Es en esta escritura donde se hallan las claves no solo para la lectura, sino tambiénconsideramos- de la escritura que plantea Antezana. Como policial, S. busca las pistas para descubrir el misterio de la muerte de $Q$. en manos de $Z$. pero para hacerlo debe traducir los manuscritos y los epígrafes de las fotos que aparecen en dichos manuscritos. Por ello, la estructura de la novela consta de prólogo y epílogo escritos por S. y la traducción en la que se "reproducen" esos manuscritos. 
Finalmente, el misterio no será resuelto, pero no por ello los pasajes escritos por S. resultan menos interesantes.

En los aportes de $S$. aparecen una serie de dualidades, de desdoblamientos, que permiten el análisis de La Toma del Manuscrito como una novela que se encuentra lejos de cualquier tradición. S. es el escritor/traductor, es decir, que es a la vez creador y reproductor. Pero la traducción no debe ser entendida solo como mera posibilidad de hacer inteligible un texto para alguien que no comparte un código cultural (en este caso la lengua). En cierta medida, el traductor también es un creador pero que se basa en una competencia diferente a la del escritor: el traductor crea a partir de la interpretación de una obra escrita por un "otro" y el escritor crea sin influencia aparente.

El mismo sistema de la traducción se presenta como un sistema de dobles, con la mediación de la interpretación. Tanto la traducción como el policial, son "géneros" que requieren de la sistematicidad y la lógica para resolver conflictos (los de la lengua y el misterio de la muerte de Q. en La Toma del Manuscrito). "Poco a poco la obra a traducir comienza a develar su lógica y su sistematicidad, sus leyes y su ritmo" (Antezana, 2008, p.13). Se persiguen huellas y rastros; en la traducción esas huellas son los trazos de las voces a ser traducidas. S. también explica en el prólogo un desdoblamiento más: "el traductor carga consigo al escritor original y a sí mismo" (p.16) y poco a poco, la traducción "fue desviándose de su cauce, convirtiéndose en reescritura y llegando a ser ficción" (p.17). Así, escritor y traductor se fusionan y anulan el desdoblamiento inicial.

Ahora bien, observamos que el valor del diseño de una novela como traducción, en las claves que establecemos en nuestra investigación, radica en entender que escribir una novela como traducción implica ya en sí misma una ruptura con respecto a la tradición que coloca al escritor fuera de Bolivia. No solo es una innovación en la narrativa boliviana en cuanto al género, sino que al ser el texto original un texto extranjero, permite que haya diversos abordajes al "texto original". Así, el texto pasa por el traductor y luego por la ficcionalización que este traductor hace del texto original alejando al narrador (que es traductor y escritor) de su propia territorialidad. Este recurso interno, plasmado en la novela, supone 
para el autor Sebastián Antezana, una posibilidad de alejarse de la tradición literaria boliviana, mediante el planteo de un tema novedoso, con personajes que se desarrollan en un espacio geográfico muy alejado de Bolivia.

La fotografía, aparece también como estrategia de ruptura o superación de la tradición. También, al reflexionar sobre ella, observamos que encarna en sí misma, un desdoblamiento. El ojo puesto en el lente implica la puesta en juego de otra mirada, un distanciamiento, otra forma de ver. En La toma del manuscrito, la fotografía también es un elemento que se aparta del género, que implica un aporte de "la modernidad" en la narrativa boliviana, acorde con los años de comienzo de siglo y con las nuevas tecnologías que se referencian en la novela con una importancia de época. ¿Nos quiere decir Antezana que la fotografía podría haber aparecido en la novela boliviana mucho antes y que sin embargo no lo hizo? ¿Por qué razón? ¿Es el ingreso de la fotografía en la novela la estrategia de Antezana para el ingreso a "la modernidad" de la novela boliviana? En cualquier caso, la fotografía -dentro de la lógica de la novela- acentúa el desdoblamiento, despegando de la realidad aquello que es fotografiado; se genera, también, otra mediación en el texto. Además de la interpretación que media en la traducción, la fotografía es la materialización de una realidad evocada no presente. Se capturó un momento que fue, que se "congeló" en el tiempo; la fotografía en sí es esa captura, ese dejar estático y con categoría de eterno (o hasta tanto lo soporte el material) el instante fotografiado. Es asimismo, un recorte de una realidad, algo que se elige conservar, documentar. El ojo que realiza esta selección no es el mismo ojo que ve y percibe la realidad; el fotógrafo toma de lo que ve aquel cuadro que exprese mejor aquello que quiere conservar de lo observado. La importancia del encuadre como proceso de selección radica en la posibilidad de captar un entorno en el aspecto más representativo para el fotógrafo. En La toma del manuscrito las fotografías van uniendo y enlazando no solo las historias y las anécdotas de los personajes (y con ello se va construyendo la re-creación, la ficción), sino que además une y estructura la novela toda. Son, pistas que se van regando para que el lector (o/y S.) vayan enlazando los episodios de la novela con las posibles causas del asesinato de $Q$. 
En lo que respecta a la tradición literaria boliviana, Sebastián Antezana (2012), refiriéndose al tema de la tradición literaria en Bolivia afirma que:

[se ha abandonado] la militancia política y también cierta obsesión de literaturas anteriores por querer explicar al país desde la ficción, por querer desentrañar una historia política y social que nos explicaría, por entender los procesos que nos han traído hasta donde estamos, por hacer de la literatura un laboratorio mediante el cual comprender nuestras miserias cotidianas (...) (p. 2).

En este sentido, La toma del manuscrito es una consecuencia de ese abandono, de ese alejarse lo más posible de los "preceptos" literarios anteriores. Si bien Antezana en la misma entrevista aclara que la tradición no se abandona del todo y que pervive, aunque subrepticiamente, en la narrativa contemporánea, algunos de los jóvenes autores prefieren no inscribirse en ese registro de profunda cavilación acerca de las causas de Bolivia para entenderse en este presente. De cualquier modo, reconoce que "la preocupación política siempre está allí, lo que se ha dejado un poco de lado es la idea de que la política es el camino para entendernos. En su lugar, quizá en estos años nos ocupamos más de la ficción" (Antezana, 2012, p.2).

Ficción aquí, significa apartarse de los modos de escribir y de decir empleados por los autores de principio del siglo XX. En el caso de la novela que analizamos, ficción implica situarse lejos de Bolivia, en un ambiente completamente alejado del imaginario referido a la narrativa boliviana, el empleo de una lengua modulada, perceptible y entendible para todo hablante español. Sortear la heterogeneidad propia de la problemática "nacional" para hablar de una completa, ajena y lejana realidad imperceptible e impensada para un lector boliviano. Sería el estallido de la ficción en Bolivia.

\section{Campo intelectual, textos y paratextos}

En el acápite anterior se reflexionó en torno a la tradición literaria en Bolivia atendiendo a la particularidad que presenta la novela de Sebastián Antezana. En el presente apartado se indagará en el campo cultural que contiene al autor y a su obra y se analizará en relación a La toma del manuscrito. Pierre Bourdieu (2002) en Campo de poder, campo intelectual, estudia las relaciones que se establecen entre diversos sujetos que tienen como denominador común el hecho de participar 
de diversos acontecimientos en este caso literarios. No es posible entender a una obra y a un autor fuera de un campo, fuera de su relación con otros autores y otras obras, fuera de un diálogo que avale esa producción o que la desplace hacia un lugar periférico. Estas matrices -podríamos llamarlas- de aceptación o de negación de un producto cultural tienen que ver con los efectos de legitimidad que pueden tener ciertos sujetos miembros de ese mismo campo pero que, en cuanto al establecimiento de las relaciones de poder, legitiman o no a un autor y a su obra.

En la narrativa boliviana del siglo XX, el campo intelectual boliviano podría configurarse mediante el estudio de obras ensayísticas y literarias que buscaban definir un "ser" boliviano. El problema radicó justamente en eso, en querer definir. Así se formularon categorías que pretendieron explicar, modelar y "encorsetar" características variadas para intentar construir un sujeto nacional. Los intentos fracasaron, pero el campo intelectual quedó definido a partir de sus miembros componentes como un grupo de sujetos aislados, no un movimiento literario o político, que aspiraba a dar respuesta a la pregunta sobre la definición del sujeto nacional y su impacto en la esfera de lo social y de lo político.

Durante la primera década del siglo XXI, el campo intelectual en Bolivia se configura mediante la reunión de una serie de jóvenes escritores interesados en, como se mencionó anteriormente, trascender y rodear el imaginario que impera sobre lo que se denomina literatura boliviana. Esta se entiende solo como la expresión de lo andino, con escenarios rurales e historias de costumbres. Si bien estos narradores no representan todas las expresiones literarias del momento actual $^{12}$, Ilama la atención que algunos autores, entre ellos, Antezana no

\footnotetext{
${ }^{12}$ Fuera de este análisis se encuentra la obra de los paceños Juan Pablo Piñeiro, Adolfo Cárdenas, Néstor Taboada Terán, Víctor Hugo Viscarra entre otros que tomamos en nuestra investigación para la tesis doctoral titulada "Relaciones de poder, imaginarios sociales y prácticas identitarias en la narrativa boliviana contemporánea (2000-2010)". En este sentido se puede observar lo expresado por Bourdieu en la obra que citamos cuando afirma que el campo "está estructurado como un sistema de relaciones en competencia y conflicto entre grupos, situaciones en posiciones diversas, como un sistema de posiciones sociales a las que están asociadas posiciones intelectuales y artísticas" (Bourdieu, 2002,p.1). 
referencian a Bolivia en ninguno de sus escritos ${ }^{13}$. Las ciudades pueden ser cualquier ciudad, la lengua no está matizada por acentos ni modismos, tal como hemos observado en la novela que estamos analizando. Es lo que denominamos literatura desmarcada, en el sentido de sin marcas.

En todo caso, el concepto de campo funciona para entender que "el autor no se conecta de modo directo a la sociedad, ni siquiera a su clase social de origen, sino a través de la estructura de un campo intelectual, que funciona como mediador entre el autor y la sociedad" (Bourdieu, 2002, p.1). Al respecto de este tema Sebastián Antezana (2012) en la entrevista mencionada más arriba plantea que por un lado:

La literatura boliviana está muy relegada, aunque no por falta de calidad, por cierto, sino por falta de una infraestructura literaria, editorial, periodística y en última instancia cultural que nos permita transformar nuestras letras (como lo hacen otros países) en un producto de exportación, en una marca registrada. El enclaustramiento que vivimos no lo vivimos solamente respecto a una salida al mar, sino que seguimos en un profundo y doloroso anonimato en muchas otras áreas. (p.3).

Por otro lado agrega:

Creo, sin embargo, que aquí sí las nuevas tecnologías nos ofrecen una puerta de entrada al mundo grande. Gracias a las redes sociales, los blogs, los periódicos digitales y otros, algunos escritores bolivianos son cada vez más reconocidos y pueden establecer lazos y comunicación con escritores, editores y lectores de todo el mundo (2012, p.3).

Estas afirmaciones, se condice con lo observado en cuanto a la redefinición de los espacios en relación a la virtualidad, explicitando que la conformación del campo intelectual muchas veces guarda una estrecha relación con los nuevos avances tecnológicos en cuanto a comunicación. Ahora bien, en la configuración del campo debemos tener en cuenta factores aledaños al autor y a la obra, como por ejemplo, las editoriales o los premios. En el caso de la obra La toma delmanuscrito, fue ganadora del $10^{\circ}$ Premio Nacional de Novela versión 2007 y publicada por editorial Alfaguara Bolivia. Estos datos robustecen su posición en el campo literario boliviano y además, posicionan a la novela y a su

${ }^{13}$ Tomamos aquí la novela La toma del manuscrito, La Paz: Alfaguara. 2008, El amor según. La Paz: El Cuervo.2011 y el cuento "La mujer del jinete" publicado en Magdalena González Almada (comp.) Ayni. Antología del cuento boliviano contemporáneo, Sofía Cartonera, 2013. 
autor como candidatos o aspirantes a acceder al mundo literario que se erige fuera de las fronteras bolivianas.

Los paratextos que acompañan a La toma del manuscrito aportan importantes datos para la configuración y reflexión en torno al campo literario boliviano. Williams (2009) explica que "es cierto que el establecimiento efectivo de una tradición selectiva puede decirse que depende de instituciones identificables" (p.161), es decir, la tradición se construye en relación a lo que ciertas instituciones legitimadas en campos determinados aportan con elementos constitutivos de esas instituciones. En términos generales, cuando tenemos en nuestras manos un libro, cualquiera sea su temática -exceptuando quizás aquellos de temática administrativa o de gestión de empresas-, no es habitual encontrar en las primeras páginas textos de instituciones económicas o financieras. La primera página que encabeza la novela de Antezana está firmada por la Administradora de Fondos de Pensiones (AFP) Previsión, dependiente del banco BBVA. Dicha entidad, responsable de patrocinar el Premio Nacional de Novela, afirman que: Entendemos al arte y la cultura como valores preciados para una sociedad, que promueven el progreso y la evolución de las ideas y que están íntimamente ligados al desarrollo de sus miembros. En este sentido nuestra contribución ha sido decidida y permanente (Antezana, 2008).

En este fragmento se hace alusión al discurso dominante imperante, con mayor énfasis, durante los primeros cuarenta años del siglo XX en Bolivia, pero que es posible rastrear a lo largo de todo el siglo pasado: el progreso y la evolución de las ideas. Este paradigma de pensamiento es el que se ha puesto en crisis con la asunción de Evo Morales en 2005. La idea de progreso no está incluido en el discurso dominante actual; en todo caso, hay una discusión en torno a qué entienden como progreso las masas indígenas y cholas de Bolivia. Volviendo al texto, se explicita una idea de progreso: el avance social está ligado a las artes y a la literatura. En este caso, fomentada por una institución financiera que juega un papel importante en la sociedad, un rol fuertemente político y que al apoyar económicamente el premio dice algo más con ese gesto. En ese sentido, se puede inferir que se trata de un premio que con el postulado citado 
anteriormente entiende la literatura como una herramienta de progreso, pero por supuesto, no se trata de cualquier expresión literaria sino que la novela premiada significa un aporte a "la evolución de las ideas" siempre y cuando se trate de una expresión acorde con preceptos de progreso, incluso, de retorno a la esperanza de constitución nacional a partir de sujetos letrados. El premio como premio en sí, se considera aquí, que cumple la función de posicionar a un sujeto en su campo, de legitimarlo y de hacerlo visible para otros sujetos del mismo campo. En ese sentido, llamó la atención el paratexto que cierra la edición de La toma del manuscrito: el acta del jurado.

A juicio de los miembros del jurado, La toma del manuscrito se plantea con una estrategia narrativa sólida y original, las historias y los personajes se convierten en la excusa para contar por el solo placer de hacerlo, historias que se inician pero que no terminan y que se entrelazan para formar un todo armónico, sobrio pero cargado de humor, donde la presencia de la intertextualidad y el tema de la escritura como reescritura y/o traducción enriquece la novela al colocar al texto "bajo sospecha" permanente. (Antezana, 2008, página de cierre).

Según nuestra lectura, los jurados quieren resaltar es que el texto de Antezana resulta un aporte a la historia de la literatura boliviana. Este se halla justamente en que es una novela con un tema poco visitado en la narrativa boliviana, una innovación de tema y estilo; lo que se premia es la literatura desmarcada de la antes mencionada; una literatura nueva, fresca en contraposición a:

La virgen de los deseos [que] se presenta como una obra bien concebida, en la que un tema recurrente en la literatura es tratado de una manera novedosa, y personajes sólidos se destacan con fuerza en el espacio local de algunos barrios de la ciudad de La Paz, en los que se mezclan tradiciones, lenguajes, seducciones y culturas. (Antezana, 2008).

El fragmento citado forma parte del acta en la que los miembros del jurado (académicos y editores reconocidos en el campo literario boliviano) justifican haberle otorgado a la obra de Néstor Taboada Terán la primera mención. Si se lee el subtexto, se observa un claro mensaje que pretende resaltar que el premio no puede homenajear una obra de "tema recurrente" en la narrativa boliviana. En tal sentido es posible afirmar que si bien en la novela de Taboada Terán aparecen las capas populares de la ciudad de La Paz, con sus barrios y sus "personajes típicos", La virgen de los deseos desde nuestro análisis, contribuye con elementos 
más que "novedosos" en el tratamiento del tema de la novela. El aporte de Taboada Terán tiene que ver más con una ruptura relacionada con el imaginario desde el que se había construido la figura de la chola en la narrativa del siglo XX. Aunque la novela pueda parecer de tema ya visitado, en realidad se trata de una obra que vuelve a poner a una chola como personaje central pero lo hace postulando un punto de vista ideológico y político que la diferencia del tratamiento utilizado en los años 1940. Por tal razón, desde nuestra opinión, sí es novedoso el tema por tratarse de un enfoque completamente diferente en cuanto al rol social y simbólico de la chola y de la ciudad. Ahora bien, no sería posible, desde los términos empleados en este trabajo, afirmar que la novela de Taboada Terán se adscribe a la tradición literaria. En este caso, hay una reformulación de esa tradición porque pese a las declaraciones del jurado, se encuentra que se trata de una reformulación, de una nueva contextualización pero que no necesariamente implica escribir literatura al modo tradicional. Más allá de estas disquisiciones, el jurado no opinó favorablemente acerca de La virgen de los deseos estableciendo de ese modo una posición política e ideológica fuertemente marcada por el campo intelectual boliviano.

La toma del manuscrito no solo se aparta de los temas que forman parte de la tradición sino que además se separa de toda referencia a la cultura popular boliviana. Ambas obras son muy diversas y ejemplifican lo que se mencionó respecto a la literatura desmarcada y su oposición la literatura marcada; en el primer caso, encontramos a La toma del manuscrito y en el segundo a La virgen de los deseos. En cuanto a la situación que otorga el mismo premio de posibilitar que la obra ganadora sea publicada por el sello Alfaguara, editorial legitimada en el campo literario, le permite a los escritores trascender las fronteras literarias bolivianas y posibilita la apertura de nuevos mercados para ellos. . La relevancia y la visibilidad que otorga el publicar con Alfaguara, significa no solo para Sebastián Antezana sino para muchos escritores bolivianos más, la posibilidad de salida hacia un mundo literario menos restringido que el nacional. 
Sin embargo, desde la perspectiva del propio autor, los componentes que integran el campo intelectual boliviano presentan recursos insuficientes materiales y simbólicos- que no alcanzan para sostener un circuito literario dinámico como sucede en otros países. Al respecto manifiesta Antezana (2012):

Todo lo que hay se reduce a unos cuantos premios serios (el nacional de novela auspiciado por la española Santillana y un grupo de medios privados, el nacional de cuento -auspiciado por una alcaldía y una editorial- y el nacional de poesía auspiciado por otra alcaldía y otra editorial-). Fuera de eso, los demás premios son uno peor que el otro (el de Santa Cruz y Cochabamba) y no hay nada más. En Bolivia no existe, como sí lo hace en Argentina, una industria cultural. La cultura siempre ha sido un quehacer artesanal, individual, autogestionado y que casi no genera ganancias. Así el panorama. (p.4).

Desde el punto de vista del autor, los premios se categorizan en "serios" y premios de menor jerarquía en los cuales Antezana no participa. Asimismo, aparece la referencia de países a los que considera con un desarrollo cultural más relevante. En estas respuestas se ponen en evidencia los imaginarios y las posiciones en el campo intelectual que le parecen más relevantes al autor; éstas, a su vez, funcionan como legitimadoras de su obra y de su posición en dicho campo. En tal sentido, resulta interesante complejizar lo expresado con los conceptos vertidos por Jorge Torres Roggero en Dones del canto (2005). En un pasaje de dicha obra el autor analiza la frase "¡Hay que estar (ahí)...!" afirmando que en el seno de esta frase se puede encontrar una condicionalidad elíptica. Esta categoría trata de explicar el vacío que se produce en los textos cuando no hay una relación entre el estar ahí (presente, asentado en el suelo) y lo que se expresa en la obra. Torres Roggero explicaque ese abismo, ese hueco que se encuentra en el discurso debe ser llenado semánticamente y que en ello radica la sabiduría. Estos enfoques tienen que ver con la práctica ampliamente extendida de creer que lo que se encuentra fuera de lo popular o fuera de lo que se relaciona con la propia cultura es mejor. Aquí se ponen en juego los imaginarios que tienen que ver con construcciones en las que lo extranjero, por ejemplo, es más valorado que lo propio.

Estos imaginarios han sido cuidadosamente construidos a fines de sostener una condición colonial en Latinoamérica y han sido alimentadas por las aristocracias y las burguesías locales. La oposición que plantea Torres entre el 
estar y el no estar (con una clara alusión a los conceptos vertidos por Rodolfo Kusch) explican por qué es importante leer la novela de Antezana en esta clave; la condición elíptica explica la necesidad de trascender lo propio, el suelo (que en este caso sería la ciudad de La Paz, sus calles, las costumbres de los paceños, las fiestas, en fin, las manifestaciones de la cultura popular que atraviesan la ciudad), y adquirir una condición cosmopolita. Antezana no escribe solo para Bolivia, sino desde Bolivia para el mundo, esperando que si en su novela se anulan o desdibujan aquellos elementos sociales y políticos que son particulares de Bolivia (únicos e irrepetibles) podrá lograr un lugar como escritor internacional sin el encorsetamiento de una nacionalidad o un escenario que lo definan. Logra Antezana conjurar lo propio para licuarlo en el contexto internacional y su obra responde a ese objetivo.

\section{Algunas conclusiones}

Finalmente y por lo expresado, La toma del manuscrito es una obra que se encuentra desmarcada y que se halla fuera de la tradición. En este sentido, es pertinente aclarar que se aparta de la tradición literaria a los fines de trascender o apartarse de una forma de escribir recurrente en la narrativa boliviana. Sin embargo, ello no significa que Antezana no se inscriba la tradición universal. El policial es una estrategia narrativa muy utilizada y existen numerosos ejemplos al respecto. Este autor suponemos, confía en que la incorporación de una lógica narrativa diferente le permita "hablar de otras cosas" y trascender el debate político tan caro a la narrativa de principios del siglo XX.

La fotografía conserva -sin fosilizar- un momento, unos personajes, un ambiente; los epígrafes que aparecen junto a ellas en la novela, se abren para crear una narración que puede escapar a lo que la fotografía dijo en el momento de ser tomada. Además, permite una creación y re-creación de relatos, historias, discursos ajenos en este caso a lo narrado con anterioridad en la literatura de Bolivia y juntamente con la traducción como estrategia narrativa, es una vía hacia otras culturas, en este caso europeas, que permitan, también, "hablar de otras cosas". Esta traducción es una forma de decir en códigos que le pertenezcan al autor y en este caso se une una Europa y un África de colonizadores a una Bolivia 
ausente en el texto. Estos elementos pueden ser recuperados a la luz del concepto de Torres Roggero en cuanto a la condicionalidad elíptica que se presenta en La toma del manuscrito. Consideramos que aun sin que Bolivia aparezca dejando rastros en la novela, la obra y su autor no escapan a lo que de bolivianos pueden tener en su ser y hacer cotidiano. La traducción, según esta lectura, se puede pensar en sentido inverso: se traduce Bolivia para desterrar los imaginarios vinculados a lo andino, al altiplano y a lo indígena.

\section{Referencias Bibliográficas}

Antezana, S. (2012). Entrevista realizada por Magdalena González Almada, 07 de mayo. Mimeo.

Antezana, S. (2008). La Toma del Manuscrito. La Paz: Alfaguara.

Antezana, S. (2011). El amor según. La Paz: El Cuervo.

Antezana, S. (2013). La mujer del jinete. En M. González Almada (comp.). Ayni Antología del cuento boliviano contemporáneo. Córdoba: Sofía Cartonera.

Bourdieu, P. (2002). Campo de poder, campo intelectual. Itinerario de un concepto. Buenos Aires: Montressor.

González Almada, M. (2013). Mestizaje y procesos sociopolíticos en la narrativa boliviana del siglo XX. En P. Heredia (Comp.). El pueblo en la trama. Modelizaciones estéticas de la cultura popular en la literatura y el pensamiento argentinos y latinoamericanos. Córdoba: Babel.

González Almada, M. (2012). Sujetos y Voces en tensión. Perspectivas para pensar la narrativa boliviana de los siglos XX y XXI. Córdoba: ImprentICA.

González Almada, M. (2012).Territorialidades virtuales y nuevos lugares del decir: la narrativa andina en tiempos de la web. Silabario. Revista de Estudios y Ensayos Geoculturales, 14 (15). Córdoba: Babel.

González Almada, M. (2012). La categoría cholo y su aplicación a la narrativa boliviana: La Virgen de los Deseos de Néstor Taboada Terán. En A propósito de la integración. Las ciencias y las humanidades desde una perspectiva crítica latinoamericana. Mendoza: Universidad Nacional de Cuyo.

Prada, A.R. (2012). Escritos Críticos. La Paz: IEB. 
Torres, J. (2002). Elogio del Pensamiento Plebeyo. Geotextos: el pueblo como sujeto cultural en la literatura argentina. Córdoba: s/d.

Torres, J. (2005). Dones del canto. Cantar, contar, hablar: geotextos de identidad y poder. Córdoba: Ediciones del Copista.

Williams, R. (2009). Marxismo y Literatura. Buenos Aires: Las cuarenta. 